\title{
Construction and performance evaluation of a conventional solar distiller
}

\author{
Abderrahmane Khechekhouche ${ }^{1 *}$, Nabil Elsharif ${ }^{2}$, Imad Kermerchou $^{3}$, Ali Sadoun ${ }^{4}$ \\ ${ }^{1}$ Applied mathematical and energies unit (AME), University of El Oued, Algeria \\ ${ }^{2}$ Mechanical Engineering Department, University of Benghazi, Libya \\ ${ }^{3}$ Laboratory of Analysis and Control of Energy Systems and Networks, University of Laghouat, Algeria \\ ${ }^{4}$ Department of Electronics, University of Sidi Bel Abbès, Algeria
}

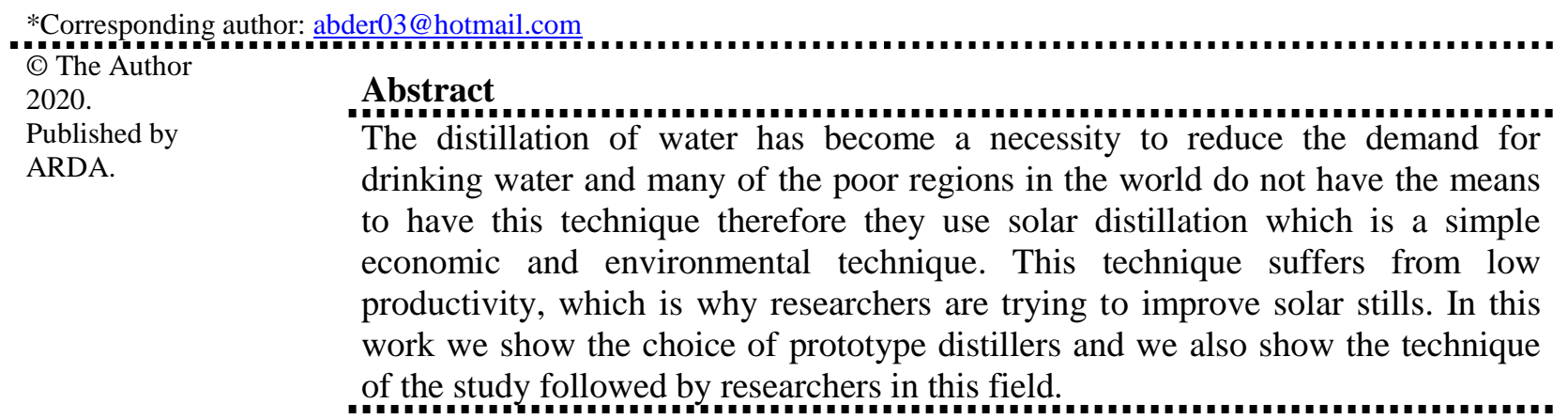

Keywords: solar energy, solar distiller, pure water, drinking water, water productivity

\section{Introduction}

Freshwater supply is a big problem in many arid regions of the world, especially in the Greater Maghreb countries. In the southeastern region of Algeria - El Oued province; the water is affected by a high fluoride content which makes the water undrinkable. This big problem pushes the inhabitants to buy filtered water coming from the stations which use the electrical energy as source. Solar distillation is a very economical solution to help solve this problem. Solar energy is one of the most promising applications for seawater desalination [1]. A very large number of studies have been carried out to improve the productivity of solar distillers supported by a large investment of research laboratories around the world [2]. Solar stills are energy systems that operate easy thanks to solar energy equipped with a heat absorbing radiation [3-6]; this device can be a viable alternative for water disinfection [7] for human consumption from sources without any purification treatment. The greenhouse effect causes a temperature inside the distiller on the order of 50 to 60 ${ }^{\circ} \mathrm{C}[8,9]$. Experimental and theoretical studies show that solar distillers have a maximum percentage of efficiency of the order of 30 to $35 \%$. This value is, of course, dependent on several factors such as the environmental radiation, the temperature of the environment and the speed of the wind, the thickness of the glazing, the variation of water depth [10-13]. In general, the researchers in the field give their results directly and are clearly given their evaluation method, in our study we first show how to build a conventional solar still starting from boards and arriving at the end at then we also show how we prepare these distillers for evaluation tests. If the distillers have the same temperature changes and they have the same amount of pure water productivity then the distillers are good for experiments.

\section{Material and methods}

\subsection{Construction of solar distiller}

Solar distillers can be constructed of various materials and selecting the suitable material is very important. Wood is the most commonly used material for the bottom and sidewalls of the distiller whereas the transparent cover can be either glass or plastic. 
1. First all sidewalls and the base of the distiller are cut to sizes as shown in Figure 1. All sidewalls and the base of the distiller are solidly combined by nailing or screwing all edges of the parts together and applying water-resistant glue between joints of the framework.

2. In order to make the distiller a leakage-free, a thin layer of a rubber sealant is applied on the inner surface of the distiller, and then evened out using a brush or scraper. This rubber sealant is a water-resistant, mould-resistant, heat-resistant sealant. It is recommended to apply black rubber sealant or black coating on the distiller's basin liner to improve the absorption of the solar radiation.

3. Distillate-collecting channel is made of a plastic pipe. A hacksaw is used to cut the plastic pipe to the correct length (bottom of the frame's length). The pipe is marked with correct slot dimensions, which should be sufficient to insert the glass cover through it, and angle grinder is used to cut the slot into the pipe work. A 90-degree PVC pipefitting (elbow) is applied on one end of the plastic pipe and glued into position using plastic glue. In addition, a PVC stop cab is used to close the other end.

4. Notches are hack sawed into outer frame then shaped and smoothened with a wood file to a radius matches the plastic pipe. The plastic pipe is positioned in its place with small inclination towards the end which has the elbow.

5. A transparent glass or polymer cover with correct dimensions is placed on the top of the framework and the lower part of the cover is inserted inside the plastic pipe. A rubber gasket should be applied on all edges to made the distiller airtight and prevent hot vapor escaping.
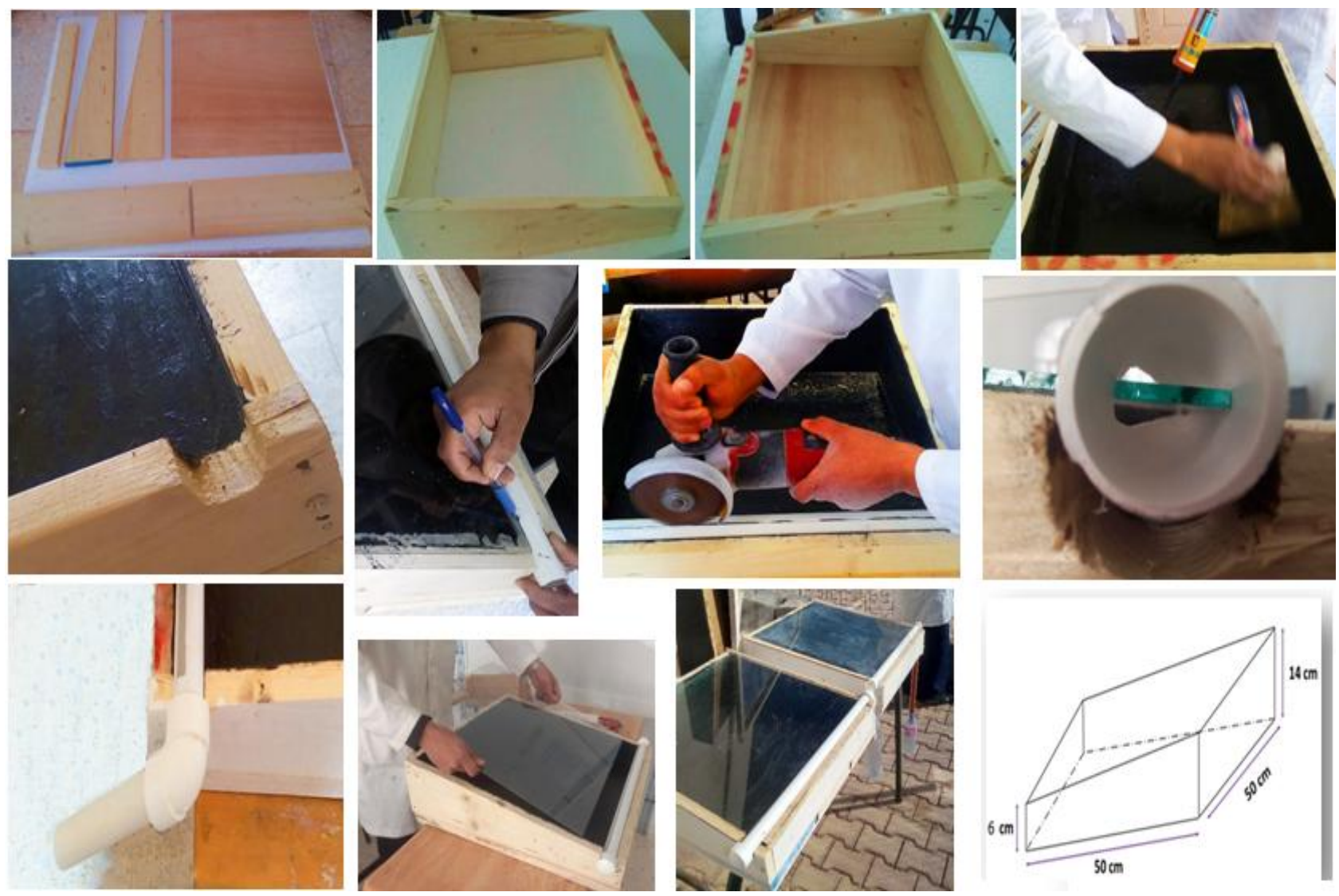

Figure 1.Steps of building a conventional solar still

\subsection{Operating principle of solar distiller}

Solar distiller is the most simple and cheap solar-driven device which can be utilized to convert saline water into potable water. The operating principle of solar distiller is based on the same processes which cause the fall of rain in nature, namely evaporation and condensation processes. Brackish water in the blackened-basin of the distiller is heated up by the solar radiation which enters the enclosure of the distiller through its inclined glass cover and leads to evaporation of the water. When the generated vapor comes in contact with the inner surface of the sloping cover which is at lower temperature, the freshwater water vapor gets condensed. 
Eventually, the condensed pure water trickled down towards the trough at the bottom edge of the glass cover and collected in a suitable container ad shown in Figure 2.

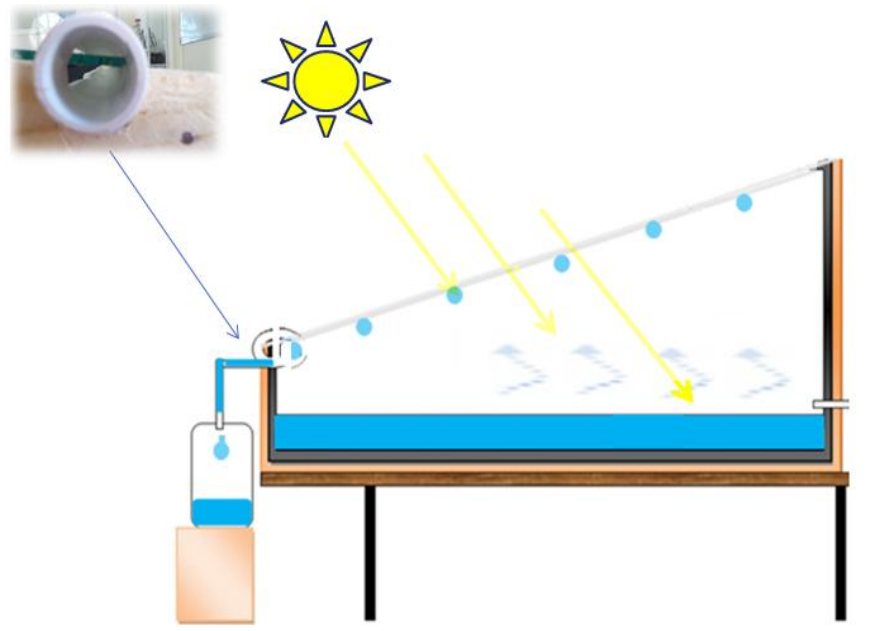

Figure 2. Operating principle of solar distiller

\subsection{The localization of the temperature sensors}

- The thermocouples are placed as shown in Figure 3:

- Thermocouple 1: emerge in water. This sensor has the role of giving the water temperature every hour.

- Thermocouple 2: place in the middle of the still for the temperature of the water vapour which moves from the water basin to the glazing.

- Thermocouple 3: place under the glazing to give the temperature of the inside of the glass.

- Thermocouple 4: place on the glazing for data the temperature of the outside of the glass.

- Thermocouple 5: place in the open air to give the ambient temperature.

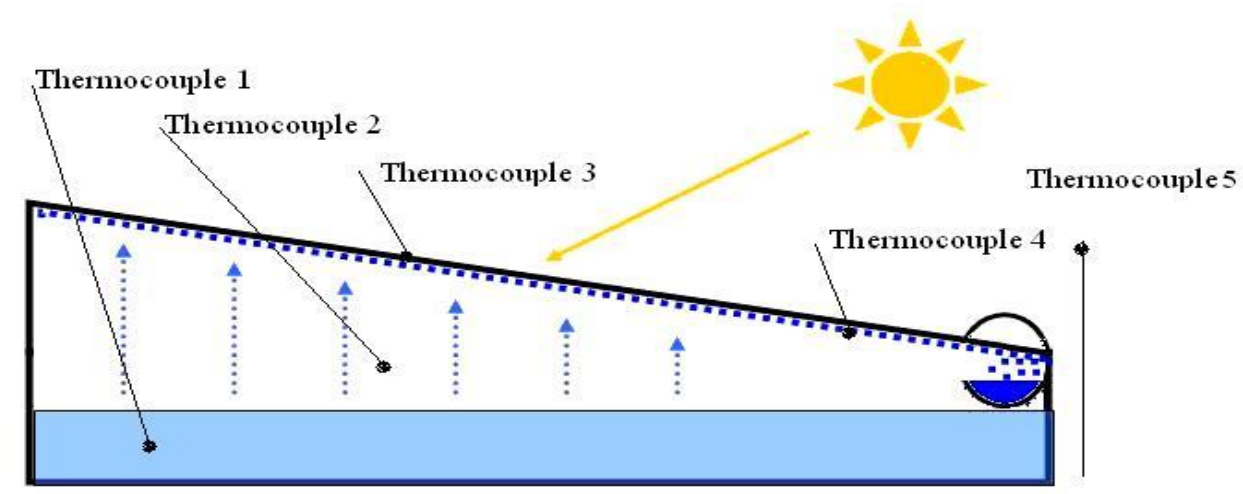

Figure 3. Localization of the thermocouples

\section{Results and discussion}

\subsection{Solar radiation and ambient temperature}

Solar radiation is detected by an electronic pyranometer placed next to the still. Figure 4a shows the evolution of solar radiation in $\mathrm{W} / \mathrm{m}^{2}$ as a function of time (h). Note the maximum radiation is between 10:00 $\mathrm{h}$ and 14:00 h. Solar radiation is the most important factor in solar distillation. Without this factor there is no production of distilled water. Figure $4 \mathrm{~b}$ shows the evolution of the ambient temperature in ${ }^{\circ} \mathrm{C}$, this factor also has an influence on the productivity of the solar still. 


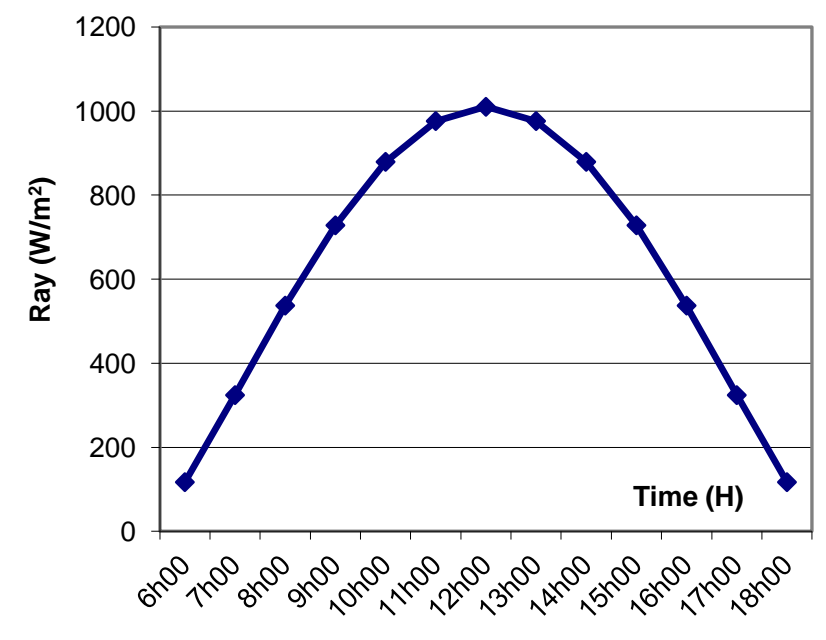

Figure 4 a.

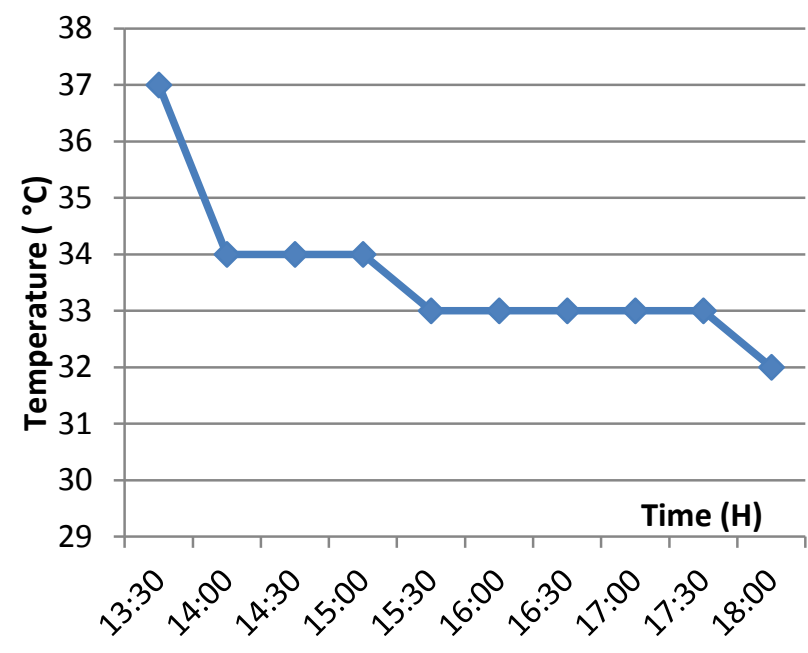

Figure $4 b$.

\subsection{The temperatures of the solar still}

Figure 5a shows the evolution of the glazing temperature of the two solar stills in ${ }^{\circ} \mathrm{C}$ (inside face). We notice that the two curves are almost similar, of course with small differences. Figure $5 b$ shows us the variation of the water temperature in ${ }^{\circ} \mathrm{C}$ of the two distillers along the experiment. We can clearly see that the two curves overlap with small deviations. These two figures are the most important in scientific research because the difference between the water temperature and the temperature of the interior face of the glazing (temperature gradient) is the secret of the pure water productivity. The larger this gap is, the greater the deliverability. In our case the temperatures are almost the same so it's a good sign that the two stills are similar.

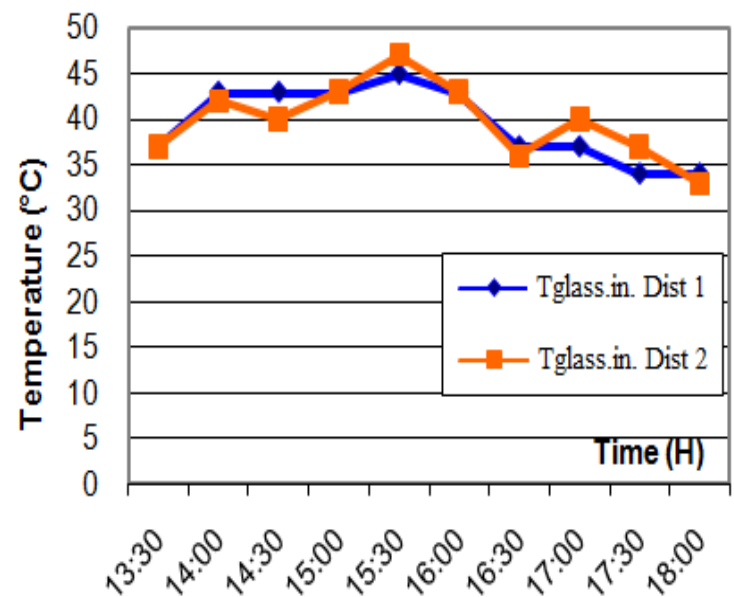

Figure 5a. Evolution of the glazing temperature

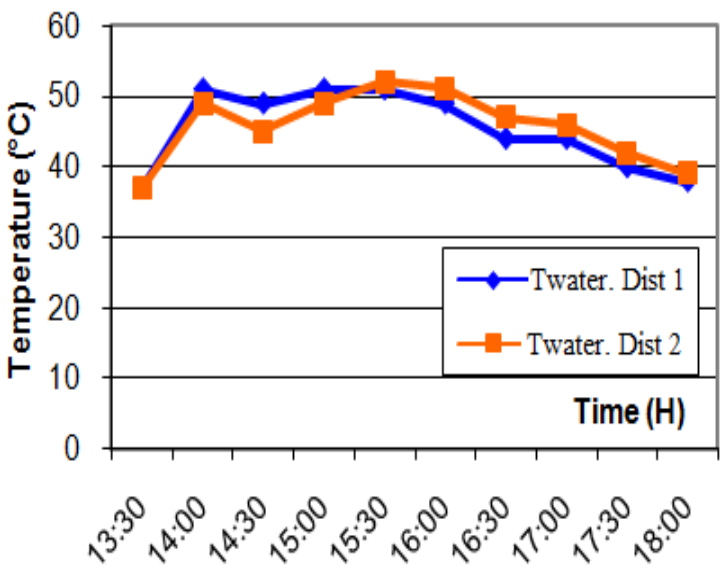

Figure 5b. Evolution of the water temperature

\subsection{Variation of the glazing temperature}

Figures $6 \mathrm{a}$ and $6 \mathrm{~b}$ show the variation of the glazing temperature (outside face) and the interior temperature of the still in ${ }^{\circ} \mathrm{C}$ as a function of time in (h). We also notice the superposition of the curves along the period of the experiment. The temperature of the external face is an influencing factor on the distillation because if the wind blows the temperature of the glazing decreases (forced convection) and the temperature gradient therefore increases which generates an increase in the productivity of pure water. For the internal temperature of the still, it is considered as an indicator which reinforces the resemblance between the two stills. 


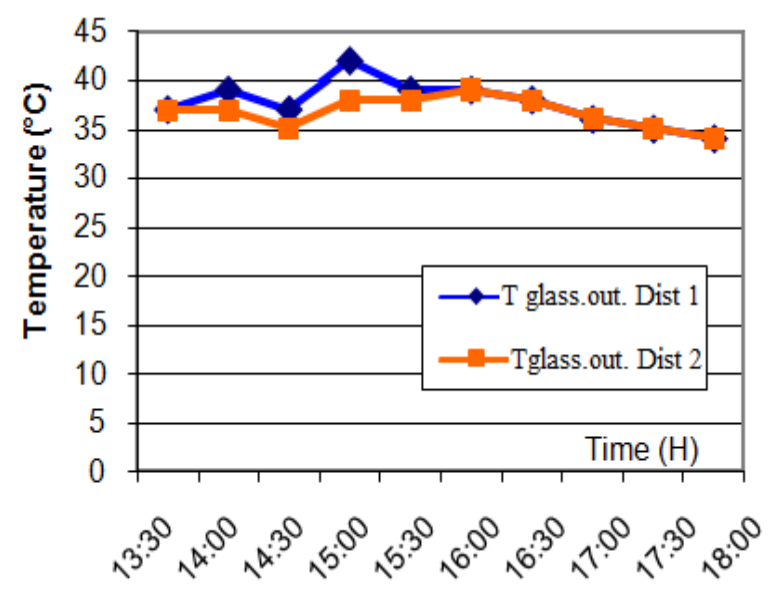

Figure 6a. variation of the glazing temperature (outside face)

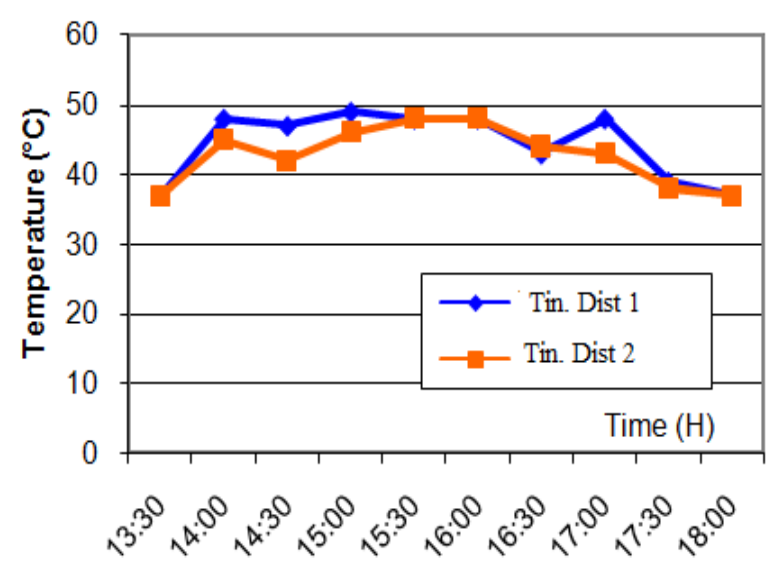

Figure $6 \mathrm{~b}$. Variation the interior still temperature

\subsection{The productivity}

The graph shows the productivity of the pure water from the two solar stills in $\mathrm{ml} / \mathrm{h}$ along the experiment and notes that the quantities of water produced each hour is almost the same. At $14: 30 \mathrm{~h}$ the quantity is $20 \mathrm{ml}$ and $19 \mathrm{ml}$. At $15.30 \mathrm{~h}$ the quantities are $30.10 \mathrm{ml}$ and $30 \mathrm{ml}$. The final amount of the $\mathrm{D} 1 \mathrm{still}$ is $178.4 \mathrm{ml} /$ day and the D2 still is $175.2 \mathrm{ml} /$ day. This result makes it possible to say that the two stills are similar.

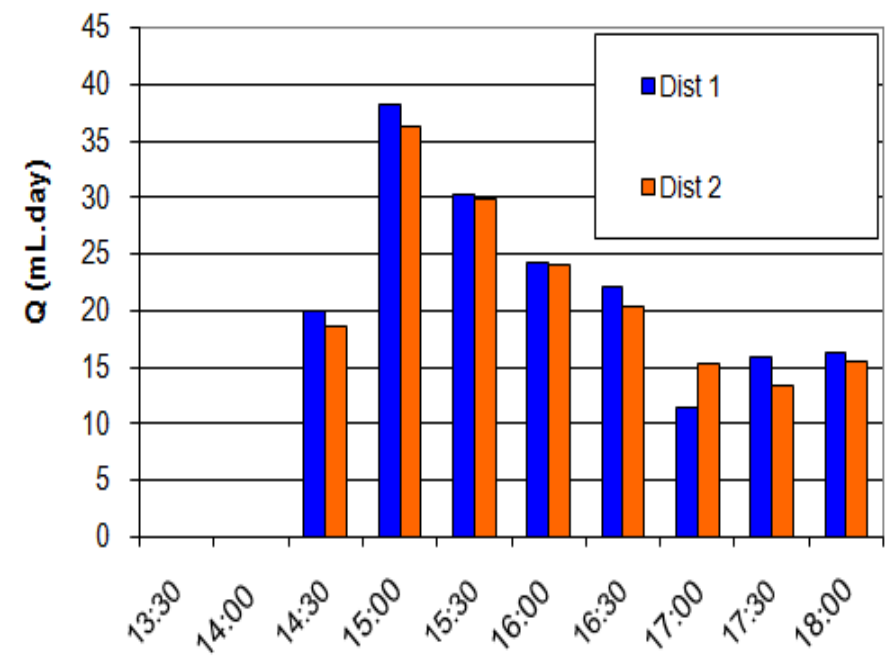

Figure 7. Productivity of the pure water

\section{Conclusion}

The results obtained confirmed that these two geometrically similar solar stills have almost the same productivity of pure water under the same metrological conditions (D1 produced $178.4 \mathrm{ml} / \mathrm{day}$ and D2 produced $175.2 \mathrm{ml} /$ day). Based on this result, we can take them without the slightest glue sticking to research study prototypes by taking one still as a witness and the other as a study object.

\section{References}

[1] Hasan F. Khazaal, Haider Th. Salim Alrikabi, Faisal Theyab Abed and Salah Ibrahim Kadhm. "Water desalination and purification using desalination units powered by solar panels". Periodicals of Engineering and Natural Sciences, vol. 7, n 3, pp.1373-1382, 2019. 
[2] L. Philip, K.S. Reddy, B. Kumar, S.M. Bhallamudi and A. Kannan, "Performance evaluation of a solar and wind aided cross-flow evaporator for RO reject management", Desalination, vol. 317, no 1, 2013.

[3] Khechekhouche Abderrahmane, Ami Boukhari, Zied Driss and Nacer Benhissen, "Seasonal effect on solar distillation in the El-Oued region of southeast Algeria", International Journal of Energetica, vol. 2, no 2, pp. 42-45, 2017.

[4] Rodrigo Poblete, Guray Salihoglu and Nezih Kamil Salihoglu, "Investigation of the factors influencing the efficiency of a solar still combined with a solar collector", Desalination and Water Treatment, vol. 57, no 60, pp. 29082-29091, 2016.

[5] M. K.Phadatare and S. K.Verma, "Influence of water depth on internal heat and mass transfer in a plastic solar still”. Desalination, vol. 217, no 1-3, pp. 267-275, 2007.

[6] A.E. Kabeel, G.B. Abdelaziz and E.M.S. El-Said, "Experimental, investigation of a solar still with composite material heat storage: Energy, exergy and economic analysis", J. Cleaner Prod., vol. 231, pp. 21- 34. 2019

[7] A. Shukla, Karunesh Kant and Atul Sharma. "Solar Still with latent heat energy storage: A review". Innovative Food Science and Emerging Technologies, vol. 41, pp. 34 -46, 2017.

[8] Abderrahmane Khechekhouche, Boubaker Benhaoua, Muthu Manokar, Ravishankar Sathyamurthy, Abd Elnaby Kabeel and Zied Driss, "Sand dunes effect on the productivity of a single slope solar distiller". Heat and Mass Transfer Journal, (in press).

[9] A. Khechekhouche, B. Ben Haoua and Z. Driss, "Solar distillation between a simple and doubleglazing", revue de mécanique. Vol. 2, no 2. 2017.

[10] A.A.F. Al-Hamadini and S.K. Shukla. "Water distillation using solar energy system with Lauric acid as storage medium”, International Journal of Energy Engineering, vol. 1, pp. 1-8, 2011.

[11] K. Swetha and J. Venugopal, "Experimental investigation of a single slope solar still using PCM", International Journal of Research in Environmental Science and Technology, vol. 1, pp. 30-33, 2011.

[12] A.A.F. Al-Hamadini and S.K. Shukla, "Modelling of solar distillation system with phase change material storage medium", Thermal Science, vol. 18, pp. 347-362, 2014.

[13] Abderrahmane Khechekhouche, Benhaoua Boubaker, Mruthu Manokar, Ravishankar Sathyamurthy and Abd Elnaby Kabeel, "Exploitation of an insulated air chamber as a glazed cover of a conventional solar still”, Heat Transfer - Asian Research, vol. 48, no 5, pp. 1563-1574, 2019. 